\title{
Time-based evaluation of bioavailable phosphorus in a calcareous soil after the application of anaerobically digested sewage sludge
}

\author{
G. Cristina $^{1} \cdot$ E. Camelin $^{1} \cdot$ S. Fraterrigo Garofalo ${ }^{1} \cdot$ F. Salomone $^{1} \cdot$ M. Pugliese $^{2} \cdot$ M. L. Gullino $^{2} \cdot$ T. Tommasi $^{1} \cdot$ D. Fino $^{1}$
}

Received: 1 October 2021 / Revised: 28 December 2021 / Accepted: 6 January 2022 / Published online: 29 January 2022

(c) The Author(s) 2022

\begin{abstract}
Nowadays, phosphorus natural reserves are being depleted, while P fertilizers demand is increasing. Phosphorus is well contained in waste materials such as sewage sludge. Only a small amount (1-3\%) of the soil total phosphorus is bioavailable for plant nutrition. More in detail, the present study focuses on the determination of the kinetics of bioavailable phosphorus concentrations in a sandy calcareous soil after the application of sewage sludge. A centrifuged (C) and dried (D) anaerobic digestate from sewage sludges obtained from the same wastewater treatment plan were separately tested to fertilize a calcareous sandy soil. Falcon tubes $(50 \mathrm{~mL})$ containing negative control $(\mathrm{T})$ and soil treated with $\mathrm{C}$ and $\mathrm{D}$ were incubated from 1 to 90 days. Soil phosphorus fractionation was performed with the SMT method and bioavailable-P was extracted through the Olsen method. Phosphorus was spectrophotometrically quantified by the molybdovanadate method. Lastly, kinetics of bioavailable-P on soils were evaluated using four kinetic models. Phosphorus fractions were constant throughout the experiment. Conversely, the bioavailable-P significantly decreased from day 1 to day 90 in $\mathrm{C}$ treatment (from $34.9 \pm 2.9$ to $23.8 \pm 1.5 \mathrm{ppm}$ ) and $\mathrm{T}$ treatment (from $4.2 \pm 1.2$ to $0.3 \pm 0.6 \mathrm{ppm}$ ). This decrease might be due to the precipitation of $\mathrm{P}$ with calcium; in fact, high concentration of $\mathrm{Ca}^{2+}$ ions and the alkaline soil $\mathrm{pH}$ can induce the sequential formation of calcium phosphates, even less soluble over time. Whereas D treatment showed a peak of bioavailable-P concentration on day 14 $(26.6 \pm 3.0)$. This trend could be due to organic carbon compounds, competitive sorption and metal bridging. The fitting of experimental data revealed that the Elovich model best described the adsorptive-precipitate process of bioavailable-P in $\mathrm{T}\left(r^{2}=0.90\right)$ and $\mathrm{C}\left(r^{2}=0.93\right)$. Conversely, none of the models satisfactorily described the behavior of bioavailable-P in D samples. This study increases the knowledge on P-related phenomena for designing and optimizing fertilizers and reducing their drawbacks such as eutrophication.
\end{abstract}

Keywords Sewage sludge anaerobically digested $\cdot$ Calcareous soil $\cdot$ Bioavailable phosphorus $\cdot$ Elovich equation $\cdot$ SMT

\section{Introduction}

Phosphorus $(\mathrm{P})$ is fundamental in plant nutrition and, in general, in many vital life processes [1]. Nowadays, phosphorus reserves are being depleted [2], while P fertilizers demand increases [3]. Furthermore, the phosphorus used in fertilizers is mainly derived from non-renewable

M. Pugliese

massimo.pugliese@unito.it

T. Tommasi

tonia.tommasi@polito.it

1 Department of Applied Science and Technology (DISAT), Politecnico Di Torino, 10129 Torino, TO, Italy

2 Agroinnova, University of Torino, Largo Paolo Braccini 2, 10095 Grugliasco, TO, Italy resources (such as phosphate rocks) $[4,5]$ with heavy environmental costs of extraction [6]. Also, it is well contained in renewable resources such as sewage sludge anaerobically digested (SSAD). To better explore this feedstock as a phosphorus source, this paper will explain how and how much of the phosphorus contained in SSADs can effectively increase phosphorus availability in soils. Other studies have already demonstrated that an increase in soil $P$ could happen with SSAD addition [7]. In the present study, the experiment focuses on phosphorus changing over time. Total phosphorus (P-Tot) in soil surfaces is less abundant than nitrogen and potassium, and (P-Tot) in soil surfaces can range from about 0.005 to $0.15 \%$ [8]. Moreover, the quantity of P-Tot in soils has little or no relationship with the availability of plant nutrition [9] and just a little part of this percentage (1-3\%) is bioavailable 
[10]. In fact, plants can take up only the inorganic forms of $\mathrm{P}$ as anions, namely dihydrogen phosphate $\left(\mathrm{H}_{2} \mathrm{PO}_{4}{ }^{-}\right)$ and monohydrogen phosphate $\left(\mathrm{HPO}_{4}{ }^{2-}\right)$. The ionic form of $\mathrm{P}$ depends on the $\mathrm{pH}$ of soil solution: at $\mathrm{pH} 7$, they are in equilibrium; in acid soil solution $\mathrm{pH}, \mathrm{H}_{2} \mathrm{PO}_{4}^{-}$is the predominant form; at alkaline $\mathrm{pH}$, the most frequent form is $\mathrm{HPO}_{4}{ }^{2-}$ [1]. P-bioavailability is related to many soil characteristics: soil texture, organic matter content, moisture content, $\mathrm{pH}$, diffusion rates and relative rates of adsorption-desorption, precipitation dissolution reactions [11], soil chemical composition, amount of silicate clays, $\mathrm{CaCO}_{3}$, presence of $\mathrm{Fe}$ or $\mathrm{Al}$ oxides, $\mathrm{P}$ addition rates and times [12] and soil temperature [13]. Some authors claim that soil $\mathrm{P}$ can be described in terms of three generic pools $[10,14]$ :

$$
\text { Solution- } P \leftrightarrow \text { Labile }-P \leftrightarrow \text { Non-labile }-P
$$

This subdivision is usually used to describe phosphorus pools in soils in relation to plant nutrition: Solution-P is the pool with readily available $\mathrm{P}$, with soluble phosphates in soil solution; Labile-P (or Active-P) is the pool with solid inorganic and organic phosphates that are relatively easy to release in the soil solution; Non-Labile-P pool (or Fixed-P) is a slow-releasing source of phosphates, and it contains very insoluble inorganic phosphates as well as organic compounds resistant to mineralization. The reactions ruling this process are many: mineralization, desorption, dissolution, weathering, adsorption, precipitation, leaching, runoff and erosion. The experiment attempts to determine which reactions are the most important in a controlled environment. Undoubtedly, great importance is due to the method of P quantification. Many methods are available to measure phosphorus forms in soils, but in the last years the SMT methods (Standards Measurements and Testing) $[15,16]$ has increased in popularity due to the repeatability, the easiness of procedures (compared to other methods) and the non-sequential extraction of $\mathrm{P}$ [17]. In particular, this last peculiarity drove the choice for its application in this work. In fact, with three independent procedures, it is possible to measure P-Tot, to estimate organic (P-Org) and inorganic phosphorus (P-Inorg), and to quantify apatite (AP; the form associated with calcium) and non-apatite phosphorus (NAIP; the form associated with oxides and hydroxides of $\mathrm{Al}, \mathrm{Fe}$ and $\mathrm{Mn}$ ). There are many other methods currently available for $\mathrm{P}$ fractionation [18-20] but this was the only one proposed and selected by the European Community to have comparable results: in fact, a lack of uniformity in methods makes it difficult to compare the outcomes from different studies [21]. This technique is normally applied for P-fractionation in freshwater sediment [15, 22], but it can be easily adapted and applied on soils and sewage sludges [21, 23-25]. As regards bioavailable-P, many methods are well-known for quantification. The Olsen method [26] is considered the benchmark of P bioavailability due to its suitability with calcareous and alkaline soil [11]. Finally, this work aims to determine and understand all these different $P$ fractions' changes over time. Although soil P chemistry has been studied more intensively than that of any other element (excluding nitrogen), quantitative predictions of phosphate concentrations in soil are still lacking [27]. Nevertheless, some kinetic studies exist, and, taking advantage of models and kinetic studies already determined and supported by literature, the experimental data of this work have been fitted with the equations of the models. The study of kinetics of P-related phenomena are certainly a key factor to design fertilizers and to optimize their efficiency and, hence, to reduce unwanted drawbacks (e.g., eutrophication) [28]. Although kinetic can suggest retention mechanisms, soil$\mathrm{P}$ behavior's complexity makes this prospect challenging to obtain [27]. Nevertheless, it will be tried to understand and interpret the physico-chemical processes that took part during this experimental campaign. Finally, aims of this study can be summarized as follows: a) to compare, in terms of P-content and fractions, two SSAD derived from the same wastewater treatment plant (WWTP); b) evaluate the P-fractions changings over time after the addition of SSAD on sandy alkaline soil; c) evaluate which is the best model to describe the behavior of $\mathrm{P}$ fractions on sandy alkaline soil after the addition of SSAD.

\section{Materials and methods}

\subsection{Sewage sludge and soil analysis}

The SSADs used in this experiment came from a largescale wastewater treatment plant $(3,800,000$ population equivalents) located in north-west Italy. Two types of digestates were used: a centrifuged solid digestate (C) derived from a mix between primary and secondary digestate and a dried pulverulent digestate (D), obtained by the thermal treatment at $200{ }^{\circ} \mathrm{C}$ of C. Physical and chemical analysis were performed on the digestates according to Cristina et al. [29], and results are summarized in Table 1.

The soil used in this study was sampled in Grugliasco (TO), Italy ( $\left.45^{\circ} 03^{\prime} 58.4^{\prime \prime} \mathrm{N}, 7^{\circ} 35^{\prime} 32.9^{\prime \prime} \mathrm{E}\right)$. It was collected within 20 and $100 \mathrm{~cm}$ depth, sieved at $2 \mathrm{~mm}$, and sterilized at $105^{\circ} \mathrm{C}$. It was a sandy, calcareous and alkaline soil, poor in macronutrients as well as in organic matter. Physical and chemical analyses were performed according to Cristina et al. [30]. Detailed results of soil analysis are shown in Table 2. 
Table 1 Physical and chemical characterization of the centrifuged (C) and dried (D) SSADs used in the present work

\begin{tabular}{|c|c|c|c|}
\hline Parameter & Unit of measure & Centrifuged (C) & Dried (D) \\
\hline $\mathrm{pH}(1: 10)$ & & 7.3 & 6.8 \\
\hline $\begin{array}{l}\text { Electrical } \\
\text { conductivity }\end{array}$ & $\mathrm{mS} / \mathrm{cm}$ & 1069 & 1.575 \\
\hline N-Tot (Kjeldahl) & $\%$ d.m.b & 6.3 & 5 \\
\hline N- Org & $\%$ d.m.b & 5.33 & 4.75 \\
\hline $\mathrm{N}-\mathrm{NO}_{3}{ }^{-}$ & $\%$ d.m.b & $<0.01$ & $<0.01$ \\
\hline $\mathrm{N}-\mathrm{NH}_{4}^{+}$ & $\%$ d.m.b & 0.97 & 0.25 \\
\hline N-org/N-Tot & $\%$ & 84 & 94 \\
\hline Dry matter & $\%$ & 25.8 & 88.8 \\
\hline Humidity & $\%$ & 74.2 & 11.2 \\
\hline Organic matter & $\%$ d.m.b & 63.9 & 64.4 \\
\hline TOC & $\%$ d.m.b & 37.1 & 37.3 \\
\hline $\mathrm{C} / \mathrm{N}$ & & 5.9 & 7.4 \\
\hline Ashes & $\%$ d.m.b & 36.1 & 35.6 \\
\hline $\mathrm{Ca}$ & $\%$ d.m.b & 5.02 & 4.64 \\
\hline $\mathrm{Mg}$ & $\%$ d.m.b & 1.45 & 1.16 \\
\hline $\mathrm{Na}$ & $\%$ d.m.b & 0.34 & 0.19 \\
\hline $\mathrm{K}$ & $\%$ d.m.b & 0.39 & 0.18 \\
\hline $\mathrm{P}$ & $\%$ d.m.b & 6.74 & 6.26 \\
\hline $\mathrm{Fe}$ & $\%$ d.m.b & 3.99 & 3.48 \\
\hline $\mathrm{Mn}$ & $\mathrm{mg} / \mathrm{kg}$ d.m.b & 268 & 228 \\
\hline $\mathrm{Cu}$ & $\mathrm{mg} / \mathrm{kg}$ d.m.b & 406 & 396 \\
\hline $\mathrm{Zn}$ & $\mathrm{mg} / \mathrm{kg}$ d.m.b & 849 & 719 \\
\hline $\mathrm{B}$ & $\mathrm{mg} / \mathrm{kg}$ d.m.b & 52 & 41 \\
\hline $\mathrm{Pb}$ & $\mathrm{mg} / \mathrm{kg}$ d.m.b & 92 & 79 \\
\hline $\mathrm{Cr}$ & mg/kg d.m.b & 245 & 217 \\
\hline $\mathrm{Cd}$ & mg/kg d.m.b & 0.8 & $<0.1$ \\
\hline $\mathrm{Ni}$ & mg/kg d.m.b & 155 & 137 \\
\hline As & mg/kg d.m.b & 0.9 & $<0.1$ \\
\hline $\mathrm{Hg}$ & $\mathrm{mg} / \mathrm{kg}$ d.m.b & $<0.1$ & $<0.1$ \\
\hline $\mathrm{Cr}^{6+}$ & $\mathrm{mg} / \mathrm{kg}$ d.m.b & $<0.1$ & $<0.1$ \\
\hline
\end{tabular}

\subsection{Methods of phosphorus analysis in soil and sewage sludge}

Phosphorus in SSADs and soil was extracted using the SMT method (Standards, Measurements and Testing Programme), a standardized method developed and approved by the European Commission $[15,16]$. This is a modified version of the Williams protocol [31] and it allows, with three independent procedures, five $\mathrm{P}$ fractions to be extracted: total phosphorus (P-Tot), inorganic phosphorus (P-Inorg), organic phosphorus (P-Org), non-apatite inorganic phosphorus (NAIP) and apatite phosphorus (AP). For P-Tot extraction, a dry sample $\left(200 \mathrm{mg}\right.$ ) was calcined in a porcelain crucible at $450{ }^{\circ} \mathrm{C}$ for $3 \mathrm{~h}$. Once the porcelain crucible was cooled down, ashes were transferred into centrifuge tubes and $20 \mathrm{ml}$ of $3.5 \mathrm{~mol}$ $\mathrm{L}^{-1} \mathrm{HCl}$ were added. After that, centrifuge tubes were
Table 2 Physical and chemical characterization of the sandy soil used in the present work

\begin{tabular}{|c|c|c|}
\hline Parameter & Unit & Value \\
\hline Stones & - & Absent \\
\hline Sand $(2.0-0.020 \mathrm{~mm})$ & $\%$ & $94 \pm 2$ \\
\hline Silt $(0.020-0.002 \mathrm{~mm})$ & $\%$ & $3 \pm 1$ \\
\hline Clay $(<0.002 \mathrm{~mm})$ & $\%$ & $3 \pm 1$ \\
\hline Texture & - & Sandy \\
\hline $\mathrm{pH}$ & - & $8.2 \pm 0.16$ \\
\hline Electrical conductivity & $\mathrm{dS} / \mathrm{m}$ & $0.131 \pm 0.018$ \\
\hline Organic matter & $\%$ & $0.38 \pm 0.12$ \\
\hline Organic carbon & $\%$ & $0.22 \pm 0.07$ \\
\hline N-Tot (Kjeldahl) & $\mathrm{g} / \mathrm{kg}$ & $0.29 \pm 0.09$ \\
\hline $\mathrm{N}-\mathrm{NO}_{2}^{-}$ & $\mathrm{mg} / \mathrm{kg}$ & $<0,2$ \\
\hline $\mathrm{N}-\mathrm{NO}_{3}{ }^{-}$ & $\mathrm{mg} / \mathrm{kg}$ & $6.33 \pm 1.53$ \\
\hline $\mathrm{N}-\mathrm{NH}_{4}^{+}$ & $\mathrm{mg} / \mathrm{kg}$ & $3 \pm 1$ \\
\hline $\mathrm{N}-\mathrm{Org}$ & $\mathrm{g} / \mathrm{kg}$ & $0.29 \pm 0.09$ \\
\hline $\mathrm{C} / \mathrm{N}$ & & $7.6 \pm 0.2$ \\
\hline P-Olsen & $\mathrm{mg} / \mathrm{kg}$ & $1.8 \pm 1.3$ \\
\hline $\mathrm{K}_{\text {exchangeable }}$ & $\mathrm{mg} / \mathrm{kg}$ & $18 \pm 1$ \\
\hline $\mathrm{Mg}_{\text {exchangeable }}$ & $\mathrm{mg} / \mathrm{kg}$ & $15 \pm 5$ \\
\hline $\mathrm{Ca}_{\text {exchangeable }}$ & $\mathrm{mg} / \mathrm{kg}$ & $675 \pm 27$ \\
\hline $\mathrm{Na}_{\text {exchangeable }}$ & $\mathrm{mg} / \mathrm{kg}$ & $6 \pm 3$ \\
\hline $\mathrm{Fe}_{\text {available }}$ & $\mathrm{mg} / \mathrm{kg}$ & $6.7 \pm 1.1$ \\
\hline $\mathrm{Mn}_{\text {available }}$ & $\mathrm{mg} / \mathrm{kg}$ & $6.5 \pm 3.0$ \\
\hline $\mathrm{Cu}_{\text {available }}$ & $\mathrm{mg} / \mathrm{kg}$ & $0.69 \pm 0.29$ \\
\hline $\mathrm{Zn}_{\text {available }}$ & $\mathrm{mg} / \mathrm{kg}$ & $0.47 \pm 0.29$ \\
\hline CEC & $\mathrm{cmol} / \mathrm{kg}$ & $3.65 \pm 0.35$ \\
\hline
\end{tabular}

covered and stirred overnight (all overnight stirrings were performed for $16 \mathrm{~h}$ ). After $16 \mathrm{~h}$, samples were centrifuged at $2000 \mathrm{~g}$ for $15 \mathrm{~min}$. The extract was collected and analyzed for determining P-Tot. Inorganic phosphorus was determined by adding $20 \mathrm{ml}$ of $1 \mathrm{~mol} \mathrm{~L}^{-1} \mathrm{HCl}$ to a centrifuge tube containing $200 \mathrm{mg}$ of the dried sample of SSADs or treated sand. After an overnight stirring, the tubes were centrifuged at $2000 \mathrm{~g}$ for $15 \mathrm{~min}$. The extract was used to determine P-Inorg and the residue was used for P-Org extraction. In fact, demineralized water $(12 \mathrm{ml})$ was added two times to wash the residue, centrifuged at $2000 \mathrm{~g}$ for $15 \mathrm{~min}$ and the supernatant was discarded. The residue was dried at $80{ }^{\circ} \mathrm{C}$ and then transferred to a porcelain crucible. After a calcination of $3 \mathrm{~h}$ at $450{ }^{\circ} \mathrm{C}$, ashes were put into centrifuge tubes with $20 \mathrm{ml}$ of $1 \mathrm{~mol} \mathrm{~L}^{-1} \mathrm{HCl}$. Centrifuge tubes were closed and stirred overnight. After an overnight stirring of $16 \mathrm{~h}$, the tubes were centrifuged at $2000 \mathrm{~g}$ for $15 \mathrm{~min}$ and the extract was collected and analyzed for P-Org determination. To extract AP and NAIP, a sequential extraction procedure was applied: firstly, $20 \mathrm{ml}$ of $1 \mathrm{~mol} \mathrm{~L}^{-1} \mathrm{NaOH}$ were added to $200 \mathrm{mg}$ of dried sample. After stirring overnight, samples were centrifuged at $2000 \mathrm{~g}$ for $15 \mathrm{~min}$. From this 
point, $10 \mathrm{ml}$ of the extract were collected and used for NAIP extraction while the cake of centrifugation was used for AP extraction. Four $\mathrm{ml}$ of $3.5 \mathrm{~mol} \mathrm{~L}^{-1} \mathrm{HCl}$ were added to the $10 \mathrm{ml}$ of the extract and then stirred for $20 \mathrm{~s}$. The samples were let stand for $16 \mathrm{~h}$ in a covered centrifuge tube and then at centrifugation at $2000 \mathrm{~g}$ for $15 \mathrm{~min}$ was applied. NAIP was measured on the supernatant. The cake of extraction previously obtained was used for AP extraction. For two times a volume of $12 \mathrm{ml}$ of $1 \mathrm{~mol} \mathrm{~L}^{-1} \mathrm{NaCl}$ was added then stirred for $5 \mathrm{~min}$, then centrifuged at $2000 \mathrm{~g}$ for $15 \mathrm{~min}$ and finally discarded the supernatant. After that, a volume of $20 \mathrm{ml}$ of $1 \mathrm{~mol} \mathrm{~L}^{-1} \mathrm{HCl}$ was added to the solid part and the tube was covered and stirred overnight. After centrifugation at $2000 \mathrm{~g}$ for $15 \mathrm{~min}$, the extract was used for apatite phosphorus measuring. The accuracy of results obtained with the protocol was tested by comparing the sum of single fractions as suggested by Xie et al. (2011) [25], according to Eq. (2):

$P-T o t=P-I n o r g+P-O r g=N A I P+A P+P-O r g$

Available-P (Olsen-P) was extracted using Olsen method [26], a procedure suitable for acidic, alkaline soils, and also for soils with a high presence of $\mathrm{CaCO}_{3}$. Two grams of dried sample were placed into a plastic container following the method. Then, $0.5 \mathrm{~g}$ of activated carbon and $40 \mathrm{~mL}$ of $0.5 \mathrm{~mol} \mathrm{~L}^{-1}$ of $\mathrm{NaHCO}_{3}$ (with a pH of 8.5) were added. Previously, the activated carbon was washed with the solution of sodium bicarbonate to eliminate residual $\mathrm{P}$ on the activated carbon. Afterward, the plastic container was kept in agitation for $30 \mathrm{~min}$ and the solution was filtered with filters Whatman ${ }^{\circledR} \mathrm{n}^{\circ} 42$. A volume of $20 \mathrm{ml}$ of the liquid solution was collected in a plastic tube and $10 \mathrm{ml}$ of $\mathrm{H}_{2} \mathrm{SO}_{4} 1 \mathrm{~N}$ were slowly added. After $24 \mathrm{~h}$ from the addition of $\mathrm{H}_{2} \mathrm{SO}_{4}$, the bioavailable-P contained into the partially covered tube were determined. The method relies on the presence of carbonate ions in the solution that reduces the activity of $\mathrm{Ca}^{2+}$ and $\mathrm{Al}^{3+}$ with a consequent increase of phosphorus solubility. In calcareous soils, the addition of carbonate ions reduces the activity of $\mathrm{Ca}^{2+}$ which precipitates in the form of $\mathrm{CaCO}_{3}$ and, in this way, the solubility of the calcium phosphate increases along with the decrease of the $\mathrm{Ca}^{2+}$ in solution.

Phosphorus quantification, in the form of orthophosphate $\mathrm{PO}_{4}{ }^{3-}$, was determined spectrophotometrically at $430 \mathrm{~nm}$ using a Hach DR5000 spectrophotometer through the Hach molybdovanadate method (Yellow method-8114) adapted from Standard methods for the examination of water and wastewater [32]. In this method, the $\mathrm{PO}_{4}{ }^{3-}$ reacts with molybdate in an acid medium to give a phosphomolybdate complex. Vanadium in the sample causes a yellow vanadomolybdophosphoric acid to form. The intensity of the yellow color is proportional to the phosphate concentration. All reagents used had high purity (>99.5\%) and all glassware, plasticware and laboratory tools were cleaned with $\mathrm{HCl} 6 \mathrm{M}$, rinsed 3 times with deionized water, one time with milliQ water to remove all impurities and finally air-dried at $60^{\circ} \mathrm{C}$.

\subsection{Climatic chamber}

A climatic chamber was built to have a constant temperature. An insulating box was used to insulate the system thermally and a Peltier cell was exploited to maintain the chamber at a constant temperature of $25^{\circ} \mathrm{C} \pm 0.2{ }^{\circ} \mathrm{C}$. In addition, a beaker full of water was left into the chamber to keep an elevated relative humidity into it. A thermometer and a hygrometer were placed inside the chamber to monitor temperature and humidity percentage; all these data were measured and recorded into an SD-card every $2 \mathrm{~min}$.

\subsection{Experimental setup}

The soil was collected, sieved at $2 \mathrm{~mm}$ and air-dried at $105{ }^{\circ} \mathrm{C}$ for $48 \mathrm{~h}$. After that, three different treatments were performed: in C case, $3 \mathrm{~kg}$ of sandy soil were mixed with centrifuged digestate (C); in D case, $3 \mathrm{~kg}$ of sandy soil were mixed with dried digestate (D); in T case, $3 \mathrm{~kg}$ of sandy soil were used as control (T). After that, the digestates treatments were thoroughly and accurately mixed. Finally, a proper mass $(70 \mathrm{~g})$ of the mixed sand was inserted into sterilized plastic tubes and milliQ water was added to each plastic tube to reach field capacity, according to Benton Jones (2012) [1]. The concentration of P-Tot added with treatments was estimated in about $100 \mathrm{ppm}$ of P. The quantity of centrifuged digestate in $\mathrm{C}$ was $0.88 \mathrm{~g}$ on average and the quantity of dried digestate in $\mathrm{D}$ was $0.27 \mathrm{~g}$ on average. Samples were incubated in the climatic chamber for $1,3,7,14,28$, 45, 60 and 90 days. At these times, three replicates of each treatment were randomly selected and sampled. The central part of the sand contained in the plastic tubes was firstly air-dried at $105^{\circ} \mathrm{C}$ and then P-Tot, P-Inorg, P-Org, NAIP, AP and bioavailable-P were evaluated. A completely randomized disposition was used for plastic tubes in the climatic chamber. All samples stayed at $25{ }^{\circ} \mathrm{C} \pm 0.2{ }^{\circ} \mathrm{C}$ and relative humidity was between $90.0 \%$ and $99.9 \%$. Every seven days all samples were weighed and taken back to the field capacity thanks to the new milliQ water addition.

\subsection{Kinetic modeling}

Kinetics of bioavailable-P (kinetic of $\mathrm{NaHCO}_{3}$ extractable-P) on soils with T, $\mathrm{C}$ and $\mathrm{D}$ treatments were analyzed using four kinetic models: first order, second order, Elovich and power function equations according to Sparks (1989) [33] and Sinegani et al. (2011) [13] and summarized in Table 3. Excluding the power function equation, in all other 
Table 3 The kinetic equations used in the present work to fit bioavailable-P data

\begin{tabular}{llr}
\hline Model & Linear form & Equation \\
\hline First order & $\ln \left(P_{t}\right)=\ln \left(P_{0}\right)-k_{1} \cdot t$ & $P_{t}=P_{0} \cdot e^{-k_{1} \cdot t}$ \\
Second order & $\frac{1}{P_{t}}=\frac{1}{P_{0}}+k_{2} \cdot t$ & $P_{t}=\frac{P_{0}}{1+k_{2} \cdot P_{0} \cdot t}$ \\
Simple Elovich & $P_{t}=\frac{1}{\beta} \ln (\alpha \cdot \beta)+\frac{1}{\beta} \ln (t)$ & $P_{t}=\frac{1}{\beta} \ln (\alpha \cdot \beta)+\frac{1}{\beta} \ln (t)$ \\
Power function & $\ln \left(P_{t}\right)=\ln (a)+b \cdot \ln (t)$ & $P_{t}=a \cdot t^{b}$ \\
\hline
\end{tabular}

equations, the boundary conditions $t=0$ to $t=t$ and $\mathrm{P}_{\mathrm{t}}=\mathrm{P}_{0}$ to $\mathrm{P}_{\mathrm{t}}=\mathrm{P}_{\mathrm{t}}$ were applied, in which $t$ represents the time and $\mathrm{P}_{\mathrm{t}}$ the bioavailable phosphorus.

Usually, the first-order equation is expressed as [33] in Eq. (3):

$\frac{d\left(P_{t}\right)}{d t}=-k_{1} \cdot P_{t}$

$P_{t}$ represents the bioavailable phosphorus at time $t$ expressed in ppm, and $k_{1}$ (expressed in $\mathrm{h}^{-1}$ ) represents the rate constant of first-order sorption. The integrated form of Eq. (3) is expressed in Eq. (4):

$\ln \left(P_{t}\right)=\ln \left(P_{0}\right)-k_{1} \cdot t$

The second-order kinetic equation is expressed as [33] in Eq. (5):

$\frac{d\left(P_{t}\right)}{d_{t}}=-k_{2} \cdot\left(P_{t}\right)^{2}$

$P_{t}$ represents the bioavailable phosphorus at time $t$ expressed in ppm, and $k_{2}$ represents the rate constant of second-order sorption. The integrated form of Eq. (5) is expressed in Eq. (6):

$\frac{1}{P_{t}}=\frac{1}{P_{0}}+k_{2} \cdot t$

Elovich kinetic equation is expressed as [33] in Eq. (7):

$\frac{d\left(P_{t}\right)}{d_{t}}=\alpha \cdot e^{-\beta \cdot P_{t}}$

$P_{t}$ represents the bioavailable phosphorus at time $t$ expressed in ppm; $\alpha$ represents the initial adsorption rate, and $\beta$ is the desorption constant [13]. Assuming that $\alpha \beta$ $t>>1$ [34], the equation becomes as expressed in Eq. (8):

$P_{t}=\frac{1}{\beta} \cdot \ln (\alpha \cdot \beta)+\frac{1}{\beta} \cdot \ln (t)$

Power function equation is expressed as [33] in Eq. (9):

$P_{t}=a \cdot t^{b}$
$P_{t}$ is the bioavailable phosphorus at time $t ; a$ and $b$ are equation constant [13]. The linearized form is expressed in Eq. (10):

$\ln \left(P_{t}\right)=\ln (a)+b \cdot \ln (t)$

All equations used to describe kinetics were evaluated according to their coefficient of determination $\left(r^{2}\right)$ and standard error of the estimate (SE) $[8,28,33,34]$. Due to the no systematic attempt of literature to interpret the parameters resulting from $P$ kinetics [35], these parameters data will not be shown.

\subsection{Statistical analysis}

One-way ANOVA was performed separately on P-Tot and bioavailable-P results of control, centrifuged, and dried treatments. After the ANOVA, Tukey's post hoc test $(p<0.05)$ was performed. The statistical software $\mathrm{R}$ (version 3.5.1Feather Spray-2018) was used for all statistical analyses.

\section{Result and discussion}

\subsection{Total phosphorus}

Total phosphorus was measured on the sandy soil and on SSADs before the experiment. P-Tot in sandy soil was $478 \pm 12 \mathrm{ppm}$, a normal value if referred to calcareous soils [28]. Phosphorus in centrifuged SSAD resulted $2.82 \pm 0.02 \%$ (d.m.b.). and in dried SSAD was $2.98 \pm 0.01 \%$ (d.m.b.). In Fig. 1, the time course of phosphorus in non-treated soil (control) and treated with centrifuged and dried SSADs is shown. Firstly, it is worth noting that from day 1, there was an increase in phosphorus of around $100 \mathrm{ppm}$ in C and D, thanks to the addition of digestate treatments. Apparently, the mean concentration of P-Tot seems to change in different times of sampling; however, the statistical analysis allowed this possibility to be rejected. In fact, the Tukey test revealed that no significant changes (at $p<0.05$ ) occurred during experiment time. As expected, P-Tot remained constant for 90 days in all the three soils under investigation and it was in line with the literature (100-3000 ppm [36]). In fact, phosphorus is poorly soluble in the soil system $\left(<0.01 \mathrm{mg} \mathrm{P} \mathrm{L}^{-1}\right.$ [36]). For instance, it can be lost by erosion and runoff or absorbed by plants, which are all phenomena not appearing in a closed system such as the falcon tubes used in this experiment. In the closed system designed for this experiment, it could be "lost" only for leaching, moving from the upper part of the tube to the lower part: anyway, statistical analysis disclaimed this hypothesis (data not shown). 


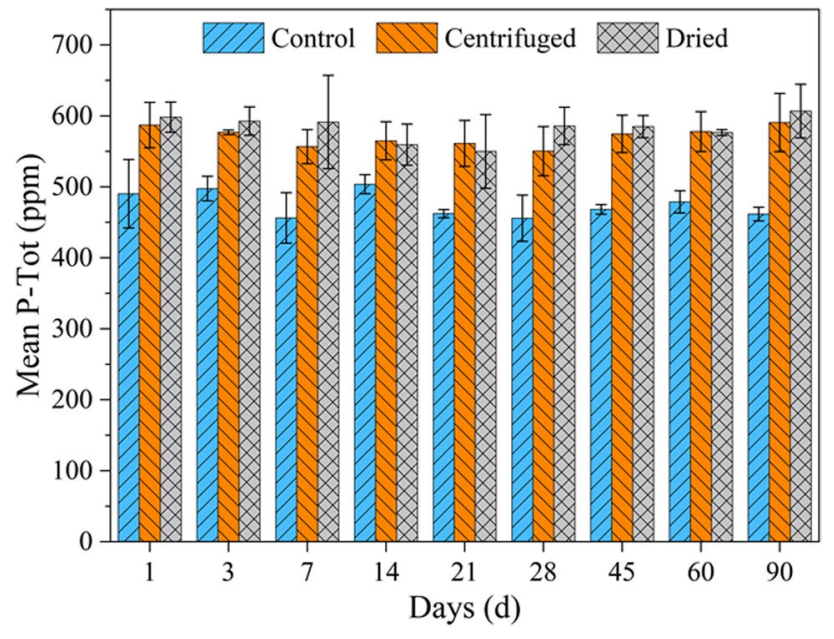

Fig. 1 Mean soil P-tot (ppm) under anaerobically digested sewage sludge (centrifuged and dried) treatments and control at 1, 3, 7, 14, $21,28,45,60$, and 90 days after the beginning of the experimental campaign. Error bars represent standard deviation $(n=3)$. No significant differences ( $p<0.05$, Tukey HSD) have been assessed within the same treatment over different times

\subsection{Phosphorus fractionation}

The fractionation of the $\mathrm{P}$ contained in SSADs revealed that most of $\mathrm{P}$ was in the inorganic form: $85.3 \%(24,033 \mathrm{ppm})$ in centrifuged digestate and $83.9 \%(25,050 \mathrm{ppm})$ in dried digestate. P-Org was 9.9\% (2779 ppm) in centrifuged and $7.1 \%$ (2107 ppm) in dried digestate (Fig. 2a). In both centrifuged and dried SSAD, there was a missing percentage of $4.8 \%$ and $9.0 \%$, respectively. Due to the sequential extraction process of the method, the SMT usually does not disclose residual $\mathrm{P}$ fractions [15]. On the other hand, it is possible to broadly compare these results to other studies on SS with similar residual parts. A study on different forms of $\mathrm{P}$ contained in sewage sludge of 46 cities and measured with the SMT method has revealed that more than $60 \%$ of P-Tot was inorganic and about 26\% was organic [37]. Another work exploiting SMT method [25] has reported that in their sewage sludges, P-Inorg ranged from 75.9 and $87.6 \%$ of P-Tot and P-Org ranged from 11.5 and $22.1 \%$ of P-Tot. GarciaAlbacete et al. (2012) [21] have analyzed heat SS with SMT method and have revealed that $87.6 \%$ of $\mathrm{P}$ was inorganic and $2.56 \%$ was organic [21]. This comparison revealed that results obtained on SS are in line with other literature studies, with P-Inorg 》P-Org. The different proportions of $\mathrm{P}$ fractions may depend on the origin and the treatment process of sludge [38], as was the case in our study. Due to the heat treatment imposed on the Dried SSAD, both total P-Org and its percentage to the total were lower than in Centrifuged SSAD and control $[38,39]$.

Concerning NAIP and AP in SSADs, the application of SMT method overestimated the results probably due to an underestimation of P-Inorg: in fact, the sum of NAIP and AP should give P-Inorg. In this study, there was an overestimation of $2.5 \%$ in centrifuged SSAD and $5.4 \%$ in dried SSAD. Mean percentages of NAIP referred to P-Inorg were $68.6 \%(16,497 \mathrm{ppm})$ and $79.4 \%(19,909 \mathrm{ppm})$ in centrifuged and dried SSADs, respectively. Mean percentages of AP related to the inorganic one were $33.9 \%$ (8137 ppm) and $25.9 \%$ (6499 $\mathrm{ppm}$ ) in centrifuged and dried digestates, respectively (Fig. 2b). As before, it is possible to broadly compare this work to the ones in the literature, since other studies have shown similar residual parts. The research on the sludges of 46 cities cited above [37] has mentioned that the mean percentage (referred to as P-Inorg) of NAIP and AP were about $78 \%$ and $26 \%$ respectively. Xie et al. (2011) [25] have reported that in their SS, NAIP ranged from 32.4 to $68.0 \%$ of P-Tot and AP ranged from 37.1 to $69.7 \%$. The work of Garcia-Albacete et al. (2012) [21] has revealed that $32.0 \%$ of inorganic P was NAIP and $51.5 \%$ was AP. In the work of Nobile et al. (2019) [38], a dewatered SSAD had $75.3 \%$ of AP and $4.8 \%$ of NAIP; in the same work, the same SSAD received a heat treatment that changed that proportion to $63.4 \%$ of AP and $18.7 \%$ of NAIP. Those different proportions of AP and NAIP could be ascribed to different
Fig. $2 \mathrm{P}$ fractionation under anaerobically digested sewage sludge (centrifuged and dried) treatments $(n=3)$. a P-Tot fractionation in the P-Inorg and P-Org components. b P-Inorg fractionation in the $\mathrm{AP}$ and NAIP components
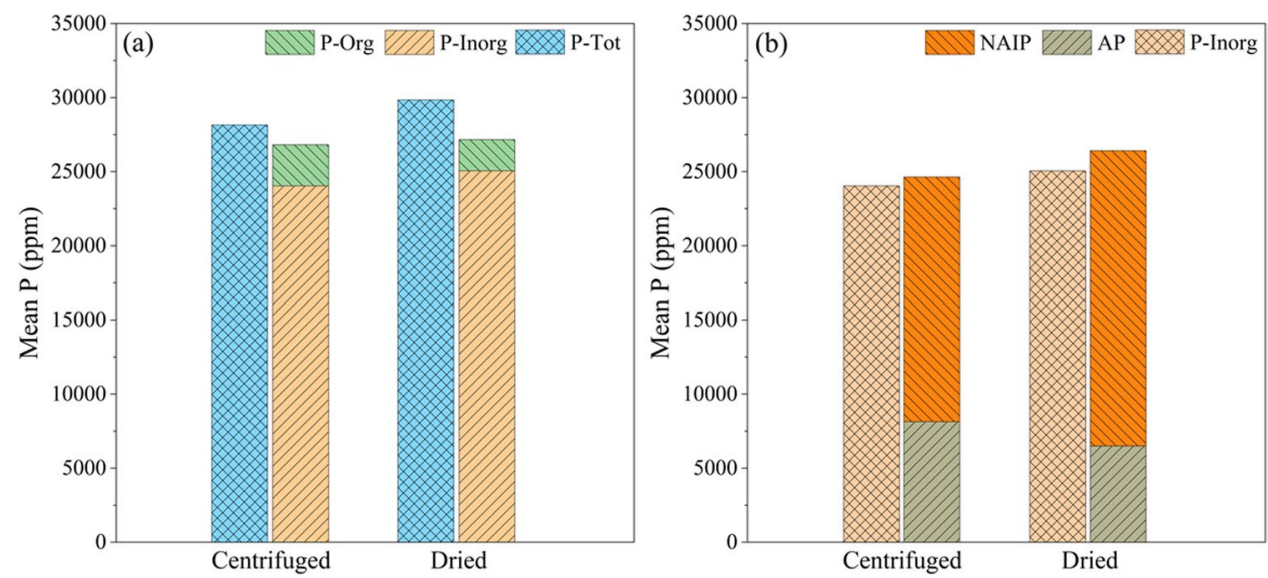
chemical and thermal treatments in WWTPs. For what it concerns chemical treatments, a large proportion of AP may be attributed to the addition of lime to improve dewatering efficiency during the sludge treatment process [25], while, on the contrary, a high presence of NAIP could be related to the iron content of the sludge [21]. Such as before, it is possible that the different percentages between centrifuged and dried SSADs in terms of NAIP and AP could be motivated by the heat treatment of the dried SSAD [38, 39]: it was demonstrated that in sludges, the heat treatment between $120^{\circ}$ and $220^{\circ} \mathrm{C}$ could increase NAIP $\%$ and decrease AP $\%$, while above $220^{\circ} \mathrm{C}$ NAIP and AP exchange rapidly their percentages [39]. SSADs used in this work derived from the same raw material; dried SSAD derived from centrifuged digestate thermally treated at around $180{ }^{\circ} \mathrm{C}$ : this treatment probably increased P-Inorg $\%$ and NAIP $\%$.

Unfortunately, the application of the SMT method to treated and non-treated soils did not give the expected results. The sum of P-Inorg and P-Org did not reach P-Tot. If in SSADs there was an "acceptable" "missing part of P" ( $<9 \%)$, during 90 days of soil study, the "missing P" had an average percentage of $23.7 \%, 26.0 \%$, and $19.9 \%$ in control, centrifuged, and dried samples, respectively. Although some authors revealed that an underestimation of the values of P-Inorg + P-Org with respect to P-Tot (between 0 and $22 \%[21,22])$ is normal, it is not correct to find any variation on these $\mathrm{P}$ fractions. By the way, in Fig. 3, the time course of P-Inorg and P-Org fractions compared to P-Tot is represented. Literature supports the thesis that after the addition of sludge to the soil, the transformation of P-Org contained in sludge into P-Inorg takes place [40]. Concerning NAIP and AP changes during the 90 days, measures were recorded on day 1, 28, 60, and 90. Nevertheless, the sum of average values of NAIP + AP was $96.1 \%, 98.8 \%$, and $86.3 \%$ of P-Inorg mean values measured on C, D, and
T samples, respectively: for this reason, it is not correct to comment on these data. In fact, if there was an underestimation of P-Inorg, it was also possible that NAIP or AP was underestimated. Anyway, a graphical representation of the sum of NAIP + AP compared to P-Inorg is reported in Fig. 4.

\subsection{Bioavailable-P}

Bioavailable- $\mathrm{P}\left(\mathrm{NaHCO}_{3}\right.$ extractable $\left.\mathrm{P}\right)$ in soil before the experiment was $4.4 \pm 1.3 \mathrm{ppm}$. This is a very low value if compared to other soils [41]. Considering that the extraction of bioavailable-P with the Olsen method is appropriate and precise only in soils, bioavailable-P was not extracted on SSADs. On the other hand, some authors assume that the bioavailable-P can be represented by the sum of NAIP and P-Org (only partially available) measured with SMT method $[17,25,42]$ : in this way, the $68.5 \%$ and the $73.8 \%$ of P-Tot of centrifuged and dried SSADs can be considered as potentially bioavailable. Surely, due to the residual-P not determined in $\mathrm{P}$ fractionation, it is not correct to compare these two percentages. It is only possible to observe that using the SMT method, most of the P contained in SSADs can be considered bioavailable. Furthermore, because of the different methods of analysis, this data cannot be directly compared to Olsen ones.

Figure 5 shows the time course of average bioavailable-P during the 90 days of the experiment. Data analysis revealed that the SSAD addition to soil increased the bioavailable-P. This result confirmed the fertilizing properties of SSADs, and it supported the results obtained in treated soils in previous experiments. This increase was supported by other studies in the literature $[35,38,43]$. The day after the addition of SSADs (Day 1), the quantity of mean bioavailable-P increased from $4.4 \pm 1.3 \mathrm{ppm}$ of the nottreated soil before the addition of SSAD to $34.9 \pm 2.9 \mathrm{ppm}$
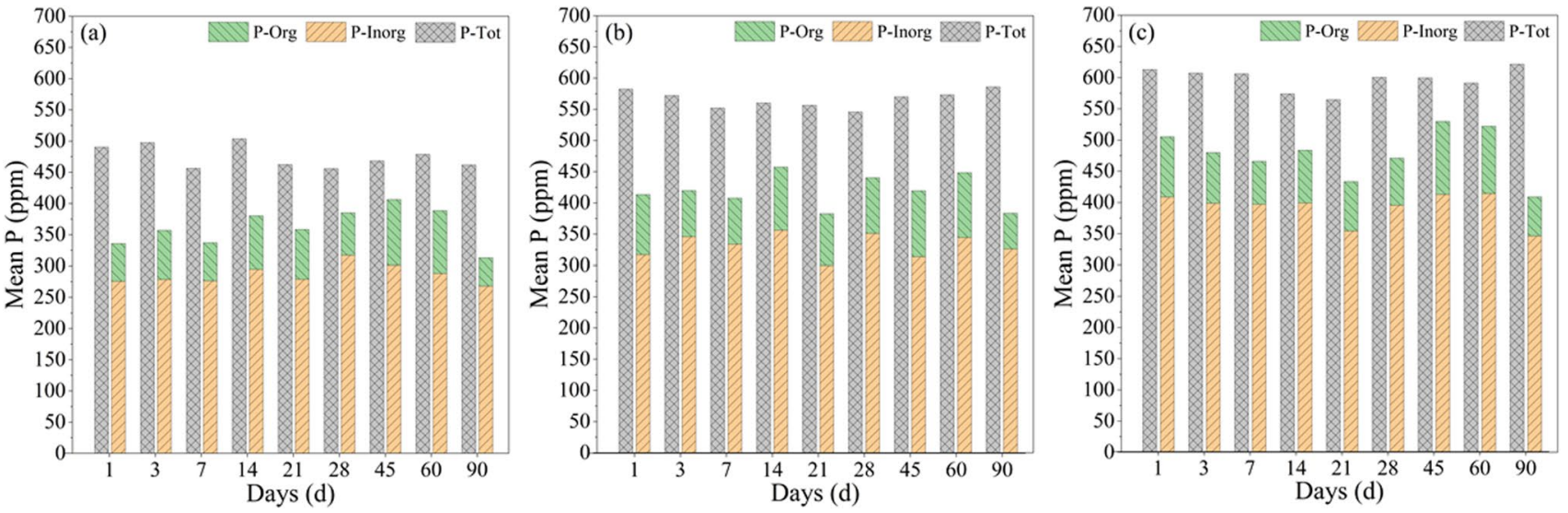

Fig. 3 Sum of mean values of inorganic and organic $\mathrm{P}$ fractions compared to mean values of P-Tot at 1, 3, 7, 14, 21, 28, 45, 60 and 90 days after the beginning of the experimental campaign $(n=3)$. a
The time course of control. b Time course of treatment with centrifuged SSAD (C). $\mathbf{c}$ Time course of treatment with dried SSAD (D) 

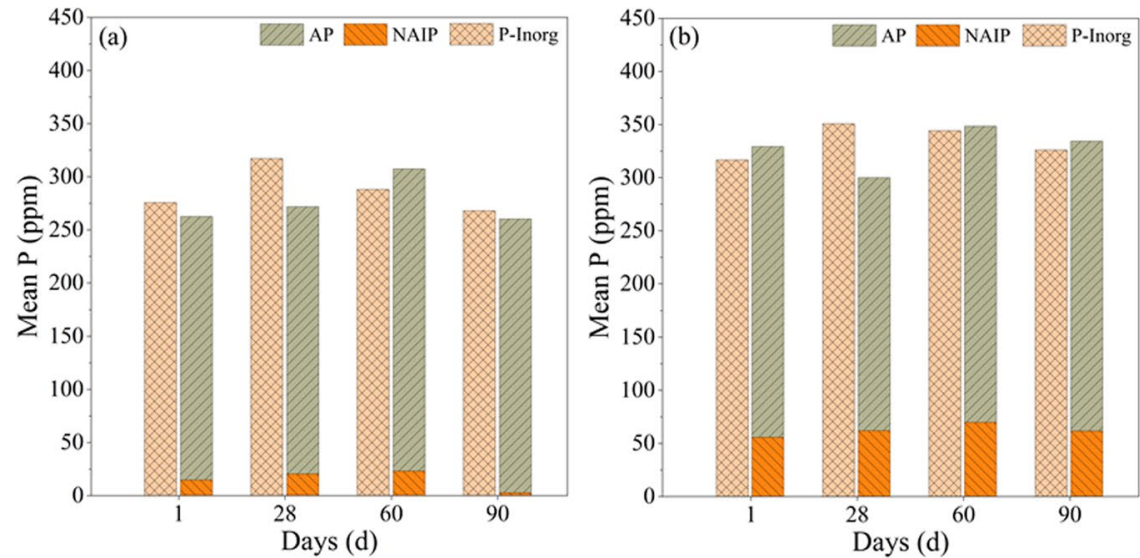

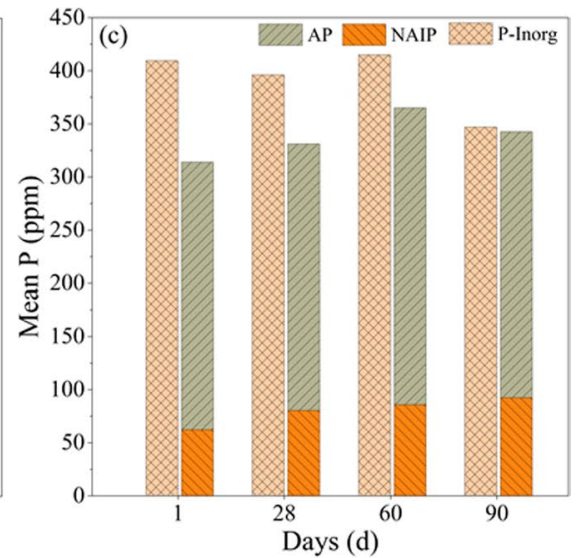

Fig. 4 Sum of mean values of NAIP and AP fractions compared to mean values of P-Inorg at $1,28,60$, and 90 days after the beginning of the experimental campaign $(n=3)$. a Time course of control.

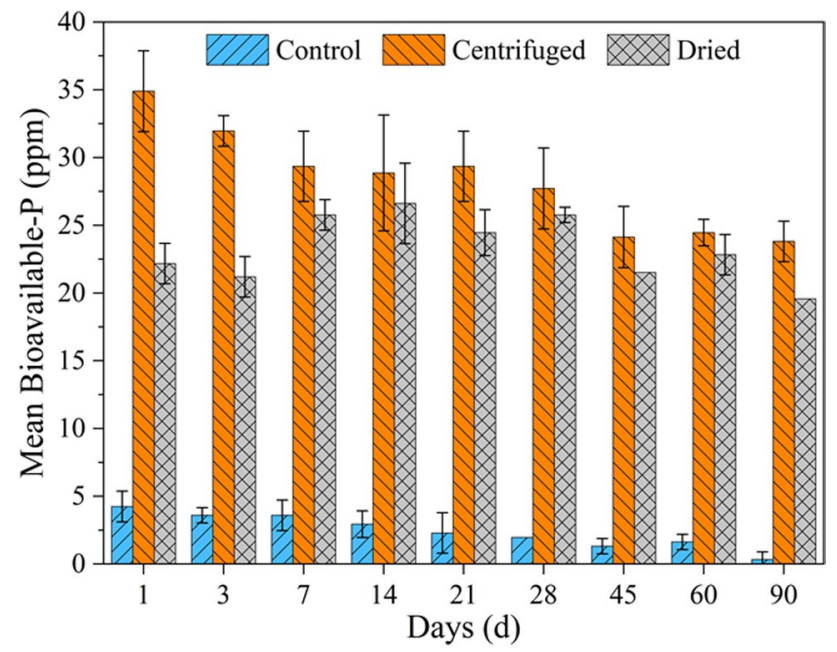

Fig. 5 Mean soil bioavailable P (ppm) under anaerobically digested sewage sludge treatments and control at $1,3,7,14,21,28,45,60$, and 90 days after the beginning of the experimental campaign. Error bars represent standard deviation $(n=3)$

of centrifuged-treated soil and to $22.2 \pm 1.5 \mathrm{ppm}$ of driedtreated soil. Considering that $100 \mathrm{ppm}$ of P-Tot were added with SSAD application, a great percentage of that can be considered as bioavailable: around $30 \%$ and $18 \%$ in centrifuged and dried SSADs, respectively. These values were lower than was expected to be bioavailable-P calculated as the sum of NAIP and P-Org. This difference can be due to two different reasons: firstly, they were extracted with two different methods, and, secondly, they were extracted after one day from $\mathrm{P}$ addition and a loss of bioavailable-P could have happened meanwhile. In the following days, a decrease in bioavailable-P in control and centrifuged treatments seemed to happen. Statistical analysis confirmed these decreasing trends (Fig. 6). b Time course of $\mathrm{C}$ treatment with centrifuged SSAD (C). c Time course of D treatment with dried SSAD (D)

Figure 6a shows the bioavailable-P gradual decrease in control soil from $4.2 \pm 1.2 \mathrm{ppm}$ of day 1 to $0.3 \pm 0.6 \mathrm{ppm}$ of day 90 . Figure $6 \mathrm{~b}$ shows the bioavailable-P decrease of soil treated with centrifuged SSAD: it decreased from $34.9 \pm 2.9 \mathrm{ppm}$ of day 1 to $23.8 \pm 1.5 \mathrm{ppm}$ of day 90 . Similar decreasing of bioavailable-P over time is well supported in the literature: in fact, similar decreasing trends were found using organic soil improvers (such as farmyard manure, processed city waste, and poultry litter [44]) and using mineral fertilizers such as $\mathrm{KH}_{2} \mathrm{PO}_{4}[13,45]$. The decrease in P-bioavailability could be motivated by many processes: immobilization, adsorption, precipitation, leaching, runoff, and erosion. Runoff and erosion must be excluded because of the closed system of the experiment. The measure of bioavailable-P in the upper, medium, and lower parts of the samples demonstrated that leaching did not appear (data not shown). Immobilization, due to the sterilization of sandy soil at $105^{\circ} \mathrm{C}$, should be excluded at least in control; on the other hand, it is possible that some microorganisms survived in centrifuged and dried SSADs. Moreover, net immobilization can occur if the substances added to soil have a $\mathrm{C} / \mathrm{P}$ ratio greater than $300: 1$, while net mineralization is likely not happening if the ratio is below 200:1 [46]. The C:P ratio of SSADs was below 200. Hence, it was also possible that the mineralization process appeared causing an increase in $\mathrm{P}$ availability, but, due to the non-increase of bioavailable $\mathrm{P}$, this option was not observed here. The most probable processes that could have happened were adsorption and precipitation.

Different trends appeared in the bioavailable-P of dried SSAD (Fig. 6c). Data analysis highlighted that from day $1(22.2 \pm 1.5 \mathrm{ppm})$ to day 90 (the lowest mean value, $19.6 \pm 0 \mathrm{ppm}$ ), there was a peak on day 14 in which the concentration of bioavailable-P was the highest $(26.6 \pm 3.0 \mathrm{ppm})$. This different trend could be due to the 

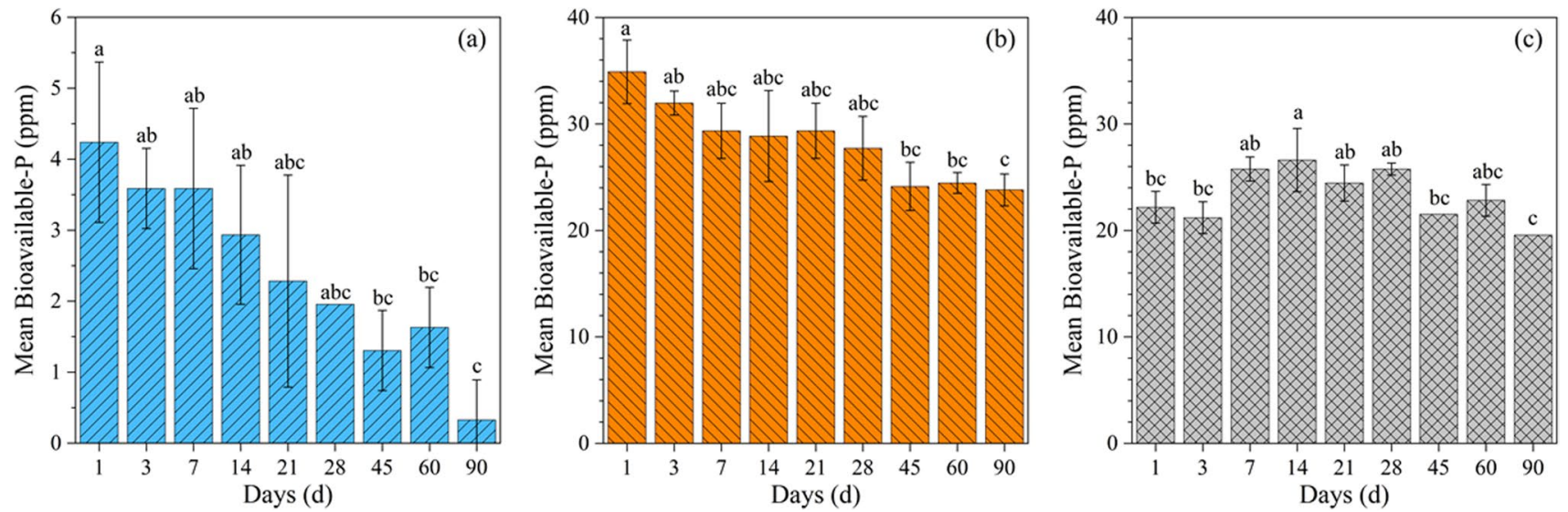

Fig. 6 Mean bioavailable-P (ppm) under anaerobically digested sewage sludge treatments at $1,3,7,14,21,28,45,60$, and 90 days after the beginning of the experimental campaign. a The time course of control. b The time course of treatment with centrifuged SSAD (C).

presence of organic matter $(\mathrm{OM})$ in SSADs. It is known that $\mathrm{OM}$ can enhance $\mathrm{P}$ bioavailability: after addition of $\mathrm{OM}$ to soil, there is an inhibition of $\mathrm{P}$ sorption, thanks to dissolved organic carbon compounds - DOC (humic acids, fulvic acids, tannic acids, aromatic acids, low molecular weight organic acids, polysaccharides, amines, and other $\mathrm{C}$ compounds [47]). DOC can release phosphorus by decreasing sorption sites on colloid surfaces by metal complexation, dissolution reaction (on $\mathrm{Fe}$ and $\mathrm{Al}$ oxides), competitive sorption, and metal bridging [48]. In soil treated with dried SSAD, probably, the DOC contained in the sludge acted slowly with one or more of these modalities. However, this explanation does not clarify why the same phenomenon did not appear in soil with centrifuged SSAD. It is possible that in $\mathrm{C}$ treatment, the effects of $\mathrm{OM}$ addition were rapid (in the first $24 \mathrm{~h}$ ), while in D treatment, these reactions were postponed due to the heat treatment. In fact, it is known that also OM characteristics changed after heat treatments [49, 50]. It is possible that the thermal treatment of SS could change carbon functional groups and, hence, also their affinity with bioavailable-P. Another conceivable hypothesis to justify this peak may be a possible anoxic condition in the sample analyzed: in fact, the release of $\mathrm{P}$ is favored under anaerobic conditions as a consequence of $\mathrm{Fe}$ reduction. These hypotheses on bioavailable-P changed over time will be better explored in the next paragraph. c The time course of treatment with dried SSAD (D). Different letters indicate differences between ppm levels significant at $p<0.05$ (Tukey HSD). Each error bar represents one standard deviation $(n=3)$

\subsection{Decreasing kinetic of phosphorus bioavailability}

Results of the coefficients of determination $\left(r^{2}\right)$ and the standard error of estimate (SE) for kinetic equations, which were used to describe phosphorus bioavailability in the poor, alkaline and sandy soil, are represented in Table 4. Firstly, the kinetic of control bioavailable-P can be well described by the first-order equation due to the high $r^{2}$ and low SE values and, secondly, by simple Elovich equation. Concerning the kinetic of bioavailable-P in the soil treated with centrifuged SSAD, the Elovich equation seems to be the best model for fitting these data due to the high $r^{2}$ (0.93). On the other hand, this model had a high SE (1.05). As well, the power equation successfully described this kinetic, with a high $r^{2}(0.91)$ and very low SE (0.04). Similarly, Sinegani et al. (2011) [13] have also found that the Elovich model best described the $\mathrm{P}$ kinetics in a sterile soil treated with $\mathrm{KH}_{2} \mathrm{PO}_{4}$. As introduced in the previous paragraph, the most probable processes that could cause a decrease in $\mathrm{NaHCO}_{3}$ extractable-P were precipitation and adsorption. Precipitation can be caused by $\mathrm{Ca}^{2+}, \mathrm{Fe}^{3+}$, and $\mathrm{Al}^{3+}$ ions. From previous analyses on the sandy soil, it resulted that total limestone was $369 \mathrm{~g} / \mathrm{kg}$, active limestone was $10 \mathrm{~g} / \mathrm{kg}$, and the exchangeable calcium was $950 \mathrm{ppm}$. With these high values of $\mathrm{Ca}^{2+}$ and a soil $\mathrm{pH}>8, \mathrm{Ca}^{2+}$ turned out to be the predominant cation and the soluble phosphorus
Table 4 Values of coefficient of determination $\left(r^{2}\right)$ and standard error of estimate (SE) for each kinetic equations used to describe the bioavailable-P data over the untreated control and treatments with centrifuged and dried SSAD

\begin{tabular}{|c|c|c|c|c|c|c|c|c|}
\hline \multirow[t]{2}{*}{ Treatment } & \multicolumn{2}{|c|}{ First order } & \multicolumn{2}{|c|}{ Second order } & \multicolumn{2}{|c|}{ Simple Elovich } & \multicolumn{2}{|c|}{ Power function } \\
\hline & $r^{2}$ & SE & $r^{2}$ & SE & $r^{2}$ & SE & $\overline{r^{2}}$ & SE \\
\hline Control & 0.91 & 0.25 & 0.73 & 0.49 & 0.90 & 0.42 & 0.64 & 0.50 \\
\hline Centrifuged & 0.79 & 0.06 & 0.82 & 0.00 & 0.93 & 1.05 & 0.91 & 0.04 \\
\hline Dried & 0.28 & 0.10 & 0.30 & 0.00 & 0.01 & 2.59 & 0.01 & 0.11 \\
\hline
\end{tabular}


can reasonably precipitate forming Ca phosphates $[8,10]$. As well as the increase of $\mathrm{pH}$ in soil solution, for the principle of Le Chatelier, the formation of Ca phosphates is favored by the increasing of $\mathrm{Ca}^{2+}$ and $\mathrm{P}$ concentrations in soil solution. Many reactions could have occurred, but, at this soil $\mathrm{pH}$, it is very probable that $\mathrm{HPO}_{4}{ }^{2-}$ quickly reacted with calcium forming a sequence of products with decreasing solubility immediately after the addition of $\mathrm{P}$ to the soil [46]. Firstly, the dicalcium phosphate (slightly soluble) was formed followed by the tricalcium phosphate (very low soluble). The reactions are expressed in Eq. (11):

$\mathrm{HPO}_{4}^{2-} \stackrel{\mathrm{CaCO}_{3}}{\rightarrow} 2\left(\mathrm{CaHPO}_{4} \cdot 2 \mathrm{H}_{2} \mathrm{O}\right)+\mathrm{CO}_{2} \uparrow \stackrel{\mathrm{CaCO}_{3}}{\rightarrow} \mathrm{Ca}_{3}\left(\mathrm{PO}_{4}\right)_{2}+\mathrm{CO}_{2} \uparrow+5 \mathrm{H}_{2} \mathrm{O}$

The solubility of these compounds and, consequently, bioavailable-Pdecreases as the phosphorus changes from $\mathrm{HPO}_{4}{ }^{2-}$ ion to tricalcium phosphate. After that, the formation of more insoluble compounds could have continued forming (in order of decreasing solubility): oxyapatite $\left[3 \mathrm{Ca}_{3}\left(\mathrm{PO}_{4}\right)_{2}\right] \cdot \mathrm{CaO}$, hydroxyapatite $\left[3 \mathrm{Ca}_{3}\left(\mathrm{PO}_{4}\right)_{2}\right] \cdot \mathrm{Ca}(\mathrm{OH})_{2}$, carbonate apatite $\left[3 \mathrm{Ca}_{3}\left(\mathrm{PO}_{4}\right)_{2}\right] \cdot \mathrm{CaCO}_{3}$, and finally fluorapatite $\left[3 \mathrm{Ca}_{3}(\mathrm{PO} 4)_{2}\right] \cdot \mathrm{CaCO}_{3}[46]$.

As introduced before, also, cations of $\mathrm{Fe}$ and $\mathrm{Al}$ can precipitate with $\mathrm{P}$ forming $\mathrm{Fe}$ and $\mathrm{Al}$ phosphates such as variscite and strengite [14] (Eqs. (12) and (13)):

$\mathrm{Al}^{3+}+\mathrm{H}_{2} \mathrm{PO}_{4(\text { aq })}^{-}+2 \mathrm{H}_{2} \mathrm{O} \rightleftarrows \mathrm{Al}\left(\mathrm{PO}_{4}\right) \cdot 2 \mathrm{H}_{2} \mathrm{O}_{(\mathrm{S})}+2 \mathrm{H}^{+}$variscite

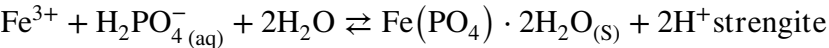

These reactions are common in acidic soils with $\mathrm{P}$ additions due to the instability of $\mathrm{Fe}$ and $\mathrm{Al}$ cations at low $\mathrm{pH}$, but in alkaline soils are rare. On the other hand, the addition of Fe salts (such as $\mathrm{FeSO}_{4} \cdot 7 \mathrm{H}_{2} \mathrm{O}$ ) is adopted in WWTPs as a strategy to remove $\mathrm{P}$ from the water via precipitation and, hence, an accumulation of Fe phosphates in SS likely occurred $[43,51,52]$. In this way, the used SSADs were rich in terms of Fe phosphates and their addition to a moist alkaline soil could have caused the dissolution of Fe phosphates, enhancing $\mathrm{P}$ in the soil solution [52]. Huang et al. (2012) [43] found that after some days from SSAD application (chemically stabilized with $\mathrm{FeSO}_{4} \cdot 7 \mathrm{H}_{2} \mathrm{O}$ ) to an alkaline soil was observed an increase of bioavailable- $\mathrm{P}$, due to $\mathrm{P}$ mineralization or mineral transformations. That could be another hypothesis explaining the enhancement of bioavailable-P after some days from the application of dried SSAD treatment. The other phenomenon that might have happened was the adsorption to $\mathrm{Al}$ and $\mathrm{Fe}$ oxides and hydroxides and the adsorption on the edges of alumino-silicate minerals. On the other hand, adsorption on oxides and hydroxides of $\mathrm{Fe}$ and $\mathrm{Al}$ and on alumino-silicate minerals tends to decrease with the increase of $\mathrm{pH}$ [14]. Differently, it was highly possible that adsorption on calcite has occurred in a calcareous soil with a basic soil $\mathrm{pH}$, rich in calcium carbonate [53, 54]. Regarding bioavailable-P kinetic with dried SSAD addition, none of the kinetic models proposed had a satisfactory fitting. On the other hand, similar results were obtained in the work of Sinegani et al. (2011) [13]: in that work, the same models tested here were satisfied for sterilized soil with $\mathrm{P}$ addition. Furthermore, in that work, there was a treatment that was not satisfied by any of the tested models: after around 20 days from $P$ addition to an unsterilized soil, there was an increase in P-bioavailability. This increase was very similar to what happened in the soil treated with dried SSAD in the present study. In that case, the authors motivated the increase of $\mathrm{P}$ with the release of organic acids (e.g., $\alpha$-keto glucuronic acid [55]) by phosphate solubilizing
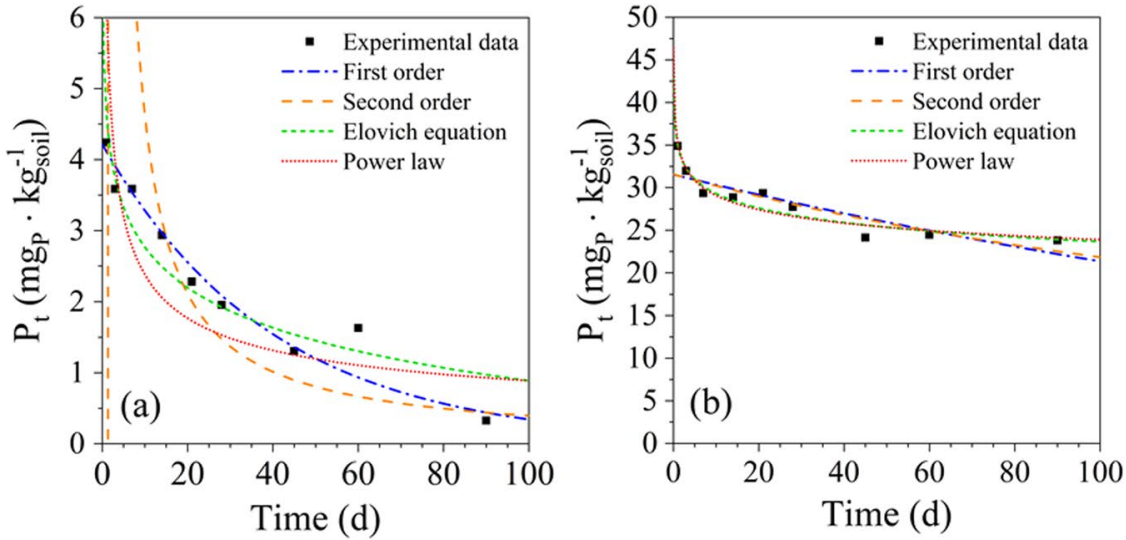

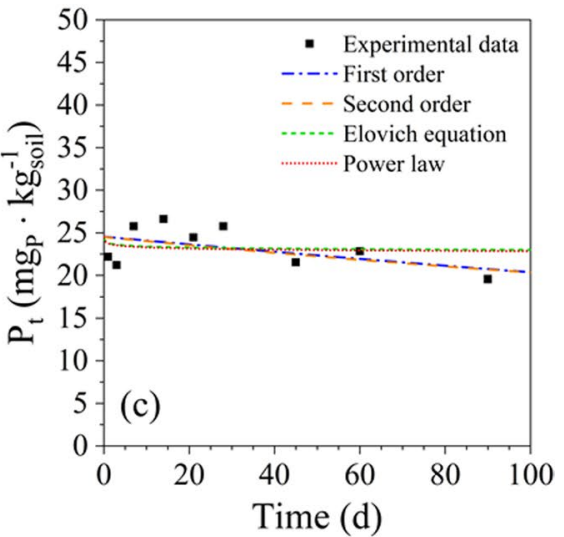

while colored lines represent the fitting to the four different kinetic models taken into account in the present study for the simulation of bioavailable-P trends 
microorganisms. These organic acids can chelate $\mathrm{Ca}, \mathrm{Fe}$, and $\mathrm{Al}$, causing an increase in the concentration of $\mathrm{P}$ in soil solution. This motivation can further explain the peak, but it is probably unrealistic for this case study due to the sterilization of soil combined with heat treatment of SSAD.

In Fig. 7, the experimental mean values of bioavailable$\mathrm{P}$ compared with values of bioavailable-P applying different kinetic models are graphically represented. It is possible to note that especially in centrifuged-treated soil, the P decreasing occurred in two stages: firstly, a rapid stage of loss of bioavailable-P and secondly, a gradual decreasing stage in which it seems that bioavailable-P reaches equilibrium. Many works reported that after an addition of $\mathrm{P}$, the equilibrium was reached in different times: in laboratory conditions from only $15 \mathrm{~s}$ [53] to 60 days [56] and until 15 years in field conditions [57]. According to the literature, the same two different stages of P-sorption by soils were observed in this work [13, 33]. The first quick stage was attributed to adsorption (ligand exchange) and the second slow stage by precipitation into increasingly less soluble states as time increases [27]. Moreover, if P concentration is high (such as in centrifuged-treated soil), ligand exchange and surface precipitation can be considered as a continuum because of a rapid $\mathrm{P}$ precipitation $[12,14,56]$. These motivations can justify the bioavailable-P decreasing kinetic obtained in control and centrifuged-treated soil. Furthermore, the use of Elovich model to describe this kinetic is totally in line with previous motivations: in fact, the Elovich model is often used to describe soils reactions (such as $\mathrm{PO}_{4}{ }^{3-}$ sorption and desorption) that could be described only by the combination of two or three first-order reactions [33, 34]. Hence, the Elovich equation can describe the probable adsorptive/ precipitate process that appeared in control and centrifuged treated soils. Finally, in a study with similar SSADs added to a similar soil, it was suggested that the rate-determining step was the precipitation of Ca-phosphates [43].

\section{Conclusion}

In this experiment, phosphorus transformations under the addition of SSADs in an alkaline soil were evaluated for a total of 90 days. However, the novelty of this work was to study and compare the kinetic of release of P-fractions added to the soil by the addition of two SSAD derived from the same WWTP and differently treated. Prior to this, fractionation of $\mathrm{P}$ in SSADs was performed and it revealed that most of it was in the inorganic form and the majority of this last was formed by NAIP, the most bioavailable fraction of P-Inorg. As expected, the addition of SSADs to soil resulted in an increase of approximately $100 \mathrm{ppm}$ in soil P-Tot. The P-Tot content remained constant for all three months of the experiment. Differently, the bioavailable-P decreased from day 1 to day 90 in control and in soil treated with centrifuged SSAD. This decrease could be due principally to the precipitation of $\mathrm{P}$ with calcium: in fact, at alkaline $\mathrm{pH}$ and with a great presence of $\mathrm{Ca}^{2+}$ ions, the formation of sequential calcium phosphates, even less soluble over time, appeared to be the principal phenomenon. Furthermore, it was even possible that $\mathrm{P}$ adsorption occurred at a lesser extent. Due to the high $\mathrm{pH}$ of soil solution, it unlikely occurred on $\mathrm{Al}$ and Fe oxides and hydroxides and alumino-silicates since it was probably adsorbed on calcite surfaces. These explanations are in line with other literature studies [8, 10, 13, 46] and with some of the models tested (Elovich equation, power function). In particular, the Elovich model, due to the high $r^{2}$ and low $\mathrm{SE}$, seems to best describe the adsorptive-precipitate process of bioavailable-P in control and centrifuged-treated soils. None of the models tested described satisfactorily the behavior of bioavailable-P in dried SSAD tested soil. In fact, on day 14 from treatment addition, there was an increment in P-bioavailability. The same behavior was also found in other works and could be caused by an anoxic environment, microorganisms, or organic matter. Heat treatment of dried SSAD probably changed organic matter functional groups, and, hence, organic matter reactivity with P. Future works will be directed on improving the techniques for phosphorus fractionation with the SMT method in order to reduce the "missing parts" of P. In this way, it will be possible to create specific time courses for all $\mathrm{P}$ fractions. Finally, it would be also important to deeply investigate the behavior of dried SSADs, in order to unequivocally define which was the cause of the enhancing of bioavailable-P 14 days after SSAD addition. In conclusion, it was possible to assess the trend of bioavailable$P$ in a calcareous sandy soil fertilized with SSAD. This work paves the way for further studies related to kinetics of P-related phenomena. Indeed, they are not only crucial to design fertilizers and to optimize their efficiency, but also to reduce drawbacks resulting from unwise fertilization such as eutrophication.

Acknowledgements The authors wish to thank Mr. Andrea Bulgarelli and Makr Shakr Srl for the design and the construction of the climatic chamber.

\section{Declarations}

Conflict of interest The authors declare no competing interests.

Open Access This article is licensed under a Creative Commons Attribution 4.0 International License, which permits use, sharing, adaptation, distribution and reproduction in any medium or format, as long as you give appropriate credit to the original author(s) and the source, provide a link to the Creative Commons licence, and indicate if changes were made. The images or other third party material in this article are included in the article's Creative Commons licence, unless indicated otherwise in a credit line to the material. If material is not included in 
the article's Creative Commons licence and your intended use is not permitted by statutory regulation or exceeds the permitted use, you will need to obtain permission directly from the copyright holder. To view a copy of this licence, visit http://creativecommons.org/licenses/by/4.0/.

\section{References}

1. Jones JB Jr (2012) Plant nutrition and soil fertility manual. Plant Nutrition and Soil Fertility Manual. https://doi.org/10.1201/ b11577

2. Gilbert N (2009) The disappearing nutrient: phosphate-based fertilizers have helped spur agricultural gains in the past century but the world may soon run out of them Natasha Gilbert investigates the potential phosphate crisis. Nature 461(7265):716-719

3. Tóth G, Guicharnaud RA, Tóth B, Hermann T (2014) Phosphorus levels in croplands of the European Union with implications for P fertilizer use. Eur J Agron 55:42-52. https://doi.org/10.1016/j. eja.2013.12.008

4. Fixen PE, Johnston AM (2012) World fertilizer nutrient reserves: a view to the future. J Sci Food Agric 92(5):1001-1005. https:// doi.org/10.1002/jsfa.4532

5. Reijnders L (2014) Phosphorus resources, their depletion and conservation, a review. Resour Conserv Recycl 93:32-49. https://doi. org/10.1016/j.resconrec.2014.09.006

6. Li L, XianJin H, Hui W, YuanHua D, Sisi X (2009) Estimation of environmental costs of chemical fertilizer utilization in China. Acta Pedol Sin 46(1):63-69

7. Cristina G, Camelin E, Tommasi T, Fino D, Pugliese M (2020) Anaerobic digestates from sewage sludge used as fertilizer on a poor alkaline sandy soil and on a peat substrate effects on tomato plants growth and on soil properties. Journal of Environmental Management 269(December 2019):110767. https://doi.org/10. 1016/j.jenvman.2020.110767

8. Fekri M, Gorgin N, Sadegh L (2011) Phosphorus desorption kinetics in two calcareous soils amended with $\mathrm{P}$ fertilizer and organic matter. Environmental Earth Sciences 64(3):721-729. https://doi. org/10.1007/s12665-010-0892-9

9. Havlin, J. L., Tisdale, S. L., Nelson, W. L., \& Beaton, J. D. (2016). Soil fertility and fertilizers. Pearson Education India.

10. Yadav, B. K., Panwar, J., Yadav, S. C., Meena, S. I., Patel, K. I., Patel, M., \& Sayeed, A. (2012). Bioavailability of soil P for plant nutrition, 10(July). https://doi.org/10.1007/978-94-007-4500-1

11. Yang JE, Jones CA, Kim HJ, Jacobsen JS (2002) Soil inorganic phosphorus fractions and Olsen-P in phosphorus-responsive calcareous soils: effects of fertilizer amount and incubation time. Commun Soil Sci Plant Anal 33(5-6):855-871. https://doi.org/ 10.1081/CSS-120003071

12. Afif E, Matar A, Torrent J (1993) Availability of phosphate applied to calcareous soils of West Asia and North Africa. Soil Sci Soc Am J 57(3):756-760. https://doi.org/10.2136/sssaj1993. $03615995005700030022 x$

13. Sinegani AA, Sedri S (2011) Effects of sterilization and temperature on the decrease kinetic of phosphorus bioavailability in two different soil types. J Soil Sci Plant Nutr 11(2):109-122. https:// doi.org/10.4067/S0718-95162011000200010

14. Penn CJ, Camberato JJ (2019) A critical review on soil chemical processes that control how soil ph affects phosphorus availability to plants. Agriculture (Switzerland) 9(6):1-18. https://doi.org/10. 3390/agriculture9060120

15. Ruban V, López-Sánchez JF, Pardo P, Rauret G, Muntau H, Quevauviller P (2001) Harmonized protocol and certified reference material for the determination of extractable contents of phosphorus in freshwater sediments - a synthesis of recent works. Anal Bioanal Chem 370(2-3):224-228. https://doi.org/ $10.1007 / \mathrm{s} 002160100753$

16. Ruban V, López-Sánchez JF, Pardo P, Rauret G, Muntau H, Quevauviller P (1999) Selection and evaluation of sequential extraction procedures for the determination of phosphorus forms in lake sediment. J Environ Monit 1(1):51-56. https:// doi.org/10.1039/a807778i

17. Wang C, Zhang Y, Li H, Morrison RJ (2013) Sequential extraction procedures for the determination of phosphorus forms in sediment. Limnology 14(2):147-157. https://doi.org/10.1007/ s10201-012-0397-1

18. Moore A Jr, Reddy KR, Hedley MJ, Stewart JWB, Chauhan Bs (1994) Role of Eh and pH on phosphorus geochemistry in sediments of Lake Okeechobee. Florida Journal of Environmental Quality 46(5):970-976

19. Williams JDH, Syers JK, Walker TW (1967) Fractionation of soil inorganic phosphate. Soil Sci Soc Am J 31(6):736-739

20. Hedley MJ, Stewart JWB, Chauhan Bs (1982) Changes in inorganic and organic soil phosphorus fractions induced by cultivation practices and by laboratory incubations. Soil Sci Soc Am J 46(5):970-976

21. García-Albacete M, Martín A, Cartagena MC (2012) Fractionation of phosphorus biowastes: characterisation and environmental risk. Waste Manage 32(6):1061-1068. https://doi.org/10. 1016/j.wasman.2012.02.003

22. Pardo P, Rauret G, López-Sánchez JF (2004) Shortened screening method for phosphorus fractionation in sediments: a complementary approach to the standards, measurements and testing harmonised protocol. Anal Chim Acta 508(2):201-206. https:// doi.org/10.1016/j.aca.2003.11.005

23. González Medeiros JJ, Pérez Cid B, Fernández Gómez E (2005) Analytical phosphorus fractionation in sewage sludge and sediment samples. Anal Bioanal Chem 381(4):873-878. https://doi. org/10.1007/s00216-004-2989-Z

24. Zhang W, Jin X, Ding Y, Zhu X, Rong N, Li J, Shan B (2016) Composition of phosphorus in wetland soils determined by SMT and solution 31P-NMR analyses. Environ Sci Pollut Res 23(9):9046-9053. https://doi.org/10.1007/s11356-015-5974-5

25. Xie C, Tang J, Zhao J, Wu D, Xu X (2011) Comparison of phosphorus fractions and alkaline phosphatase activity in sludge, soils, and sediments. J Soils Sediments 11(8):1432-1439. https://doi.org/10.1007/s11368-011-0429-1

26. Olsen SR, Cole CV, Watandbe F, Dean L (1954) Estimation of available phosphorus in soil by extraction with sodium bicarbonate. J Chem Inf Model 53(9):1689-1699. https://doi.org/10. 1017/CBO9781107415324.004

27. Bohn, H. L., O'Connor, G. A., \& McNeal, B. L. (2001). Soil chemistry. (I. John Wiley and Sons, Ed.) (3rd ed.).

28. Hosseinpur A, Pashamokhtari H (2008) Impact of treated sewage sludge application on phosphorus release kinetics in some calcareous soils. Environ Geol 55(5):1015-1021. https://doi. org/10.1007/s00254-007-1050-x

29. Cristina, G., Camelin, E., Ottone, C., Fraterrigo, S., Jorquera, L., Castro, M., ... Tommasi, T. (2020). Recovery of humic acids from anaerobic sewage sludge: extraction, characterization and encapsulation in alginate beads. International Journal of Biological Macromolecules, 164, 277-285. https://doi.org/ 10.1016/j.ijbiomac.2020.07.097

30. Cristina G, Camelin E, Pugliese M, Tommasi T, Fino D (2019) Evaluation of anaerobic digestates from sewage sludge as a potential solution for improvement of soil fertility. Waste Manage 99:122-134. https://doi.org/10.1016/j.wasman.2019.08.018

31. Williams JDH, Mayer T, Nriagu JO (1980) Extractability of phosphorus from phosphate minerals common in soils and sediments. Soil Sci Soc Am J 44(3):462-465 
32. Federation WE, Association APH (2005) Standard methods for the examination of water and wastewater. American Public Health Association (APHA), Washington, DC, USA

33. Sparks, D. L. (1989). Kinetics of Soil Chemical Processes-Academic Press.

34. Chien SH, Clayton WR (1980) Application of Elovich equation to the kinetics of phosphate release and sorption in soils. Soil Sci Soc Am J 44(2):265-268. https://doi.org/10.2136/sssaj1980. $03615995004400020013 x$

35. Islas-Espinoza M, Solís-Mejía L, Esteller MV (2014) Phosphorus release kinetics in a soil amended with biosolids and vermicompost. Environmental Earth Sciences 71(3):1441-1451. https://doi. org/10.1007/s12665-013-2549-y

36. Karamesouti, M., \& Gasparatos, D. (2017). Sustainable management of soil phosphorus in a changing world. In Adaptive soil management: from theory to practices (pp. 189-214). Singapore: Springer Singapore. https://doi. org/10.1007/978-981-10-3638-5_9

37. Wang C, Liu QW, Zhi Y, Cheng L, Wang N, Li CD, Mao YX (2019) Contents and forms of phosphorous in the municipal sewage sludge of China. Huanjing Kexue/Environmental Science. https://doi.org/10.13227/j.hjkx.201809078

38. Nobile C, Houben D, Michel E, Firmin S, Lambers H, Kandeler E, Faucon MP (2019) Phosphorus-acquisition strategies of canola, wheat and barley in soil amended with sewage sludges. Sci Rep 9(1):1-11. https://doi.org/10.1038/s41598-019-51204-X

39. Li R, Yin J, Wang W, Li Y, Zhang Z (2014) Transformation of phosphorus during drying and roasting of sewage sludge. Waste Manage 34(7):1211-1216. https://doi.org/10.1016/j.wasman. 2014.03.022

40. Tibbert, M., Smith, M. T. E., \& Cade-Menun, B. J. (2003). Phosphorus dynamics under Lolium perenne in a sandy loam soil after a single application of three different sewage sludge types from the same treatment stream. In Proceedings of 2 nd International symposium on phosphorus dynamics in the soil-plant continuum, Perth, West Australia (pp. 28-29).

41. Arpa Veneto. (2007). Capitolo 13 - Agrelan: un sistema di interpretazione dell'analisi del terreno. In L'interpretazione delle analisi del terreno - Strumento per la sostenibilità ambientale (pp. 62-67). Padova.

42. Pardo P, López-Sánchez JF, Rauret G (2003) Relationships between phosphorus fractionation and major components in sediments using the SMT harmonised extraction procedure. Anal Bioanal Chem 376(2):248-254. https://doi.org/10.1007/ s00216-003-1897-y

43. Huang XL, Chen Y, Shenker M (2012) Dynamics of phosphorus phytoavailability in soil amended with stabilized sewage sludge materials. Geoderma 170:144-153. https://doi.org/10.1016/j. geoderma.2011.11.025
44. Bibi F, Saleem I, Javid S, Ehsan S, Danish S, Ahmad I (2018) Phosphorus release kinetics of applied phosphate is influenced by time and organic sources in clay loam and sandy clay loam soils. Soil and Environment 37(2):136-142. https://doi.org/10.25252/ SE/18/20973

45. Javid S, Rowell DL (2002) A laboratory study of the effect of time and temperature on the decline in Olsen $\mathrm{P}$ following phosphate addition to calcareous soils. Soil Use Manag 18:127-134. https:// doi.org/10.1079/SUM2002116

46. Weil, R. ., \& Brady, N. C. (2017). Soil phosphorus and potassium. In The nature and properties of soils (15th ed., pp. 643-695).

47. Stevenson FJ (1994) Humus chemistry: genesis, composition, reactions. John Wiley \& Sons

48. Guppy CN, Menzies NW, Moody PW, Blamey FPC (2005) Competitive sorption reactions between phosphorus and organic matter in soil: a review. Aust J Soil Res 43(2):189-202. https://doi.org/ 10.1071/SR04049

49. Santos F, Russell D, Berhe AA (2016) Thermal alteration of water extractable organic matter in climosequence soils from the Sierra Nevada. California Journal of Geophysical Research: Biogeosciences 121(11):2877-2885. https://doi.org/10.1002/2016JG003597

50. Araya SN, Fogel ML, Berhe AA (2017) Thermal alteration of soil organic matter properties: a systematic study to infer response of Sierra Nevada climosequence soils to forest fires. Soil 3(1):31-44. https://doi.org/10.5194/soil-3-31-2017

51. Epstein, E. (2001). Land application of sewage sludge and biosolids. LEWIS PUBLISHERS.

52. Huang X-L, Chen Y, Shenker M (2007) Solid phosphorus phase in aluminum- and iron-treated biosolids. J Environ Qual 36(2):549_ 556. https://doi.org/10.2134/jeq2006.0155

53. Kuo, S., \& Loxse, E. G. (1972). Division s-2-soil chemistry.

54. Griffin R.A., \& Jurinak J.J. (1973). The interaction of phosphate with calcite. Soil Science Society of America Journal, 847-850.

55. Motsara, M. R., Bhattacharyya, P. B., \& Srivastava, B. (1995). Biofertilizers their description and characteristics. Biofertiliser Technology. Marketing and Usage. A Source Book-Cum-Glossary, Fertiliser Development and Consultation Organization. New Delhi, 9-18.

56. Chen YSR, Butler JN, Stumm W (1973) Kinetic study of phosphate reaction with aluminum oxide and kaolinite. Environ Sci Technol 7(4):327-332. https://doi.org/10.1021/es60076a007

57. Ma, Y., Li, J., Li, X., Tang, X., Liang, Y., Huang, S., ... Yang, X. (2009). Phosphorus accumulation and depletion in soils in wheatmaize cropping systems: modeling and validation. Field Crops Research, 110(3), 207-212. https://doi.org/10.1016/j.fcr.2008.08.007

Publisher's note Springer Nature remains neutral with regard to jurisdictional claims in published maps and institutional affiliations. 